\title{
Kinerja Penyuluh Pertanian Lapangan dan Tingkat Kepuasan Petani Padi di Kecamatan Metro Selatan Kota Metro
}

\section{Perfomance of Field Extension Worker and the Level of Satisfaction of Rice Farmers in the South Metro District Metro City}

\author{
Oleh: \\ Rania Pinati ${ }^{1 *}$, Sumaryo Gitosaputro ${ }^{2}$, Dame Trully Gultom ${ }^{2}$ \\ ${ }^{1}$ Jurusan Agribisnis, Fakultas Pertanian, Universitas Lampung. \\ ${ }^{2}$ Program Studi Penyuluhan Pertanian, Fakultas Pertanian, Universitas Lampung. \\ Jl Sumantri Brojonegoro 1, Bandar Lampung, 35145, Lampung, Indonesia \\ *Email: rania.pinati@gmail.com
}

Received June 26, 2020; Revised August 18, 2020; Accepted August 23, 2020

\begin{abstract}
ABSTRAK
Penelitian ini bertujuan untuk mengetahui tingkat kinerja PPL, tingkat kepuasan petani padi terhadap kinerja PPL, menganalisis faktor-faktor yang berhubungan dengan kinerja PPL dan menganalisis hubungan antara tingkat kinerja PPL dengan tingkat kepuasan petani padi. Penelitian dilakukan mulai bulan September 2019 - November 2019 di Kecamatan Metro Selatan Kota Metro. Responden pada penelitian ini adalah penyuluh dan petani padi terdiri dari empat orang penyuluh dan 63 orang petani yang dipilih secara acak. Metode analisis data menggunakan analisis deskriptif kuantitatif, tabulasi dan korelasi Rank Spearman. Hasil penelitian menunjukan bahwa kinerja PPL tergolong cukup baik. PPL cukup rutin melakukan kunjungan ke kelompok tani, membantu petani dalam pemecahan masalah dan memberikan penyuluhan sesuai dengan apa yang diharapkan oleh petani. Tingkat kepuasan petani padi terhadap kinerja PPL tergolong cukup puas. PPL sudah memberikan penyuluhan yang cukup sesuai dengan apa yang diharapkan oleh petani. Faktor-faktor yang berhubungan dengan kinerja PPL adalah masa kerja penyuluh dan ketersediaan sarana dan prasarana (gedung, laptop, lcd, kendaraan dan lain-lain). Tingkat kinerja PPL memiliki hubungan dengan tingkat kepuasan petani.
\end{abstract}

Kata kunci: Kepuasaan Petani, Kinerja Penyuluh Pertanian Lapangan,

\begin{abstract}
ABSTRAK
This research aims were to determine the extension performance, to know the level of satisfaction of rice farmers to the extension performance, to analyze the factors related to the extension performance and to analyze the relationship between the level of extension performance with the level of satisfaction of rice farmers. This research was conducted in Metro South The City Metro. Respondents were to the held study agricultural consisted of 4 extension agricultural and 63 people rice farmers who were randomly selected. Data analysis methods using quantitative descriptive analysis, tabulation and correlation Rank Spearman. The results of this research showed that the field agricultural extension performance has relatively good. The extension was quite routine to make $a$ visit to the farmer group, assisting farmers in problem solving and providing counseling in accordance with what is expected by farmers. The level of satisfaction of rice farmers on field agricultural extension performance was quite satisfied. Extension agricultural already provided adequate counseling in accordance with what the farmer expects. Factors related to the performance of field agricultural extension in this study were the term of extension agricultural and availability of facilities and infrastructure (buildings, laptops, LCD, vehicles etc.). The level of field agricultural extension performance has a relationship with the level of satisfaction of farmers.
\end{abstract}

Keywords: author Farmer's satisfaction, performance of field Farm extension 


\section{PENDAHULUAN}

Indonesia merupakan negara agraris yang sebagian besar penduduknya bermata pencaharian sebagai petani dan bertempat tinggal di pedesaan. Sektor pertanian merupakan sektor yang memiliki peran penting dalam perekonomian nasional. Subsektor tanaman pangan merupakan bagian dari sektor pertanian yang memiliki peranan penting dalam ketahanan pangan nasional. Indonesia saat ini memprioritaskan tiga jenis tanaman pangan dalam pengembangan pertanian yaitu padi, jagung dan kedelai. (Badan Ketahanan Pangan, 2016)

Provinsi Lampung memiliki beberapa daerah penghasil padi yang memiliki produktivitas cukup baik, salah satunya yaitu Kota Metro dengan jumlah produktivitas sebesar 5,40 ton/ha, diatas produktivitas rata-rata produktivitas di Provinsi Lampung yaitu sebesar 5,26 ton/ha pada tahun 2017. (Badan Pusat Statistik, 2018).

Kecamatan Metro Selatan merupakan salah satu kecamatan penghasil padi terbesar pertama di Kabupaten Metro dengan jumlah produksi pada tahun 2015 sebesar 7,505 ton dengan luas panen 1,321 ha dan tingkat produktivitas padi sebesar 5,68 ton/ha (Dinas Pertanian, Perikanan dan Kehutanan Metro, 2017).

Peningkatan produksi padi di Kecamatan Metro Selatan dipengaruhi oleh faktor seperti penggunaan benih, penggunaan pupuk, ketersediaan sarana dan prasarana dan kinerja PPL. Penyuluhan adalah suatu proses pembelajaran bagi pelaku utama serta pelaku usaha agar mereka mau dan mampu menolong dan mengorganisasikan dirinya dalam mengakses informasi pasar, teknologi, permodalan dan sumberdaya lainnya, sebagai upaya untuk meningkatkan produktivitas, efisiensi usaha, pendapatan dan kesejahteraannya serta meningkatkan kesadaran dalam pelestarian fungsi lingkungan hidup (Departemen Peranian, 2009)
Penyuluhan adalah suatu proses pembelajaran bagi pelaku utama serta pelaku usaha agar mereka mau dan mampu menolong dan mengorganisasikan dirinya dalam mengakses informasi pasar, teknologi, permodalan dan sumberdaya lainnya, sebagai upaya untuk meningkatkan prouktivitas, efisiensi usaha, pendapatan dan kesejahteraannya serta meningkatkan kesadaran dalam pelestarian fungsi lingkungan hidup .

Adapun tujuan dari penelitian ini yaitu mengetahui kinerja PPL, mengetahui tingkat kepuasan petani padi terhadap kinerja PPL, menganalisis faktor-faktor yang berhubungan dengan kinerja PPL, menganalisis hubungan antara tingkat kinerja PPL dengan tingkat kepuasan petani padi.

\section{METODE PENELITIAN}

Metode yang digunakan dalam penelitian ini adalah metode survei. Penelitian ini dilakukan di Kecamatan Metro Selatan Kota Metro. Pemilihan lokasi dilakukan secara sengaja (purposive) dengan pertimbangan bahwa Kecamatan Metro Selatan merupakan salah satu kecamatan yang ada di Kota Metro dengan produktivitas padi tertinggi pertama. Penelitian ini dilakukan pada bulan September - November 2019.

Pengumpulan data dilakukan dengan menggunakan kuisioner. Data yang dikumpulkan berupa data primer dan data sekunder. Data primer berupa data yang diambil langsung dari responden dengan instrumen kuisioner yang telah dibuat sebelum melalui wawancara. Data sekunder diperoleh dari studi literatur, laporanlaporan, dan pustaka lainnya yang berhubungan dengan penelitian ini serta lembaga instansi yang terkait dalam penelitian ini seperti BPPP.

Responden penelitian adalah petani padi pengambilan sampel diambil dari empat kelurahan yaitu Kelurahan Sumber Sari, Kelurahan Margorejo, Kelurahan Rejomulyo dan Kelurahan Margodadi. 
Penentuan sampel PPL pada penelitian ini ditentukan secara sengaja dipilih empat orang PPL dan penentuan sampel petani menggunakan metode acak sederhana (Simple Random Sampling) namun dengan ketentuan kelompok tani tersebut harus aktif mengikuti kegiatan dari BPPP Kecamatan Metro Selatan dan terpilih 63 orang padi.

Metode analisis data yang digunakan adalah metode deskriptif dan non parametrik korelasi Rank Spearman. Kepuasaan petani dianalisis dengan pendekatan tradisional Rangkuti (2006). Metode analisi deskriptif digunakan untuk menjawab tujuan pertama yaitu mengetahui tingkat kinerja penyuluh sedangkan pendekatan tradisional untuk menjawab tujuan kedua yaitu mengetahui tingkat kepuasaan petani terhadap kinerja PPL, tujuan ketiga dan keempat menggunakan statistic non parametric korelasi Rank Spearman dengan skala pengukaran ordial dan rasio.

Rumus uji Koefisien Korelasi Rank Spearman menurut Siegel (1997), adalah sebagai berikut:

$$
r s=1-\frac{6 \sum_{i-1}^{n} d i^{2}}{n^{3}}
$$

Keterangan :

$r \mathrm{~s}=$ Penduga koefisien korelasi.

$\mathrm{di}=$ Perbedaan setiap pasangan rank .

$\mathrm{N}$ = Jumlah responden .

Kaidah pengambilan keputusan adalah sebagai berikut :

1. Jika nilai signifikansi $\leq(\alpha)=0,05$ atau $(\alpha)=0,01$ maka terima $\mathrm{H}_{1}$, berarti terdapat hubungan antara kedua variabel yang diuji.

2. Jika nilai signifikansi $>(\alpha)=0,05$ atau $(\alpha)=0,01$ maka tolak $\mathrm{H}_{1}$, berarti tidak terdapat hubungan antara kedua variabel yang diuji.

\section{HASIL DAN PEMBAHASAN}

\section{Gambaran Umum Lokasi Penelitian}

Kecamatan Metro Selatan berada pada ketinggian $58 \mathrm{~m}$ di atas permukaan laut, topografi wilayah dataran rendah dengan luas wilayah $1.433 \mathrm{Ha}$. Wilayah ini terbagi atas empat kelurahan yaitu : Kelurahan Sumber Sari, Rejomulyo, Margerejo dan Mergodadi dengan Ibu Kota kecamatan adalah Kelurahan Rejomulyo. Komoditas pertanian tanaman pangan yang dibudidayakan di Kecamatan Metro Selatan antara lain adalah tanaman padi, jagung, ubikayu, ubi jalar, kacang tanah, kedelai dan kacang hijau.

\section{Keadaan Umum Responden}

Rata-rata umur responden petani padi 45 tahun, sehingga rata-rata responden pada penelitian ini tergolong pada usia produktif. Sebagian besar responden pada penelitian ini memiliki tingkat pendidikan SMP (Sekolah Menengah Pertama). Rata-rata umur responden PPL 45 tahun. Rata-rata luas lahan yang dimiliki responden petani yaitu 1 ha sedangkan untuk lama berusaha tani 10-30 tahun, untuk responden PPL ratarata memiliki masa kerja 16 tahun.

\section{Tingkat Kinerja PPL di BPPP Kecamatan Metro Selatan Kota Metro}

Pembangunan pertanian khususnya padi yang merupakan tanaman pangan sangat membutuhkan peran PPL untuk membantu petani dalam berusahatani padi sesuai dengan teknologi budidaya pertanian yang berorientasi pada pengetahuan, kemampuan dan sikap petani dalam mengadopsi teknologi pertanian.

Peraturan Mentri Pertanian Nomor 91 tahun 2013, menjelaskan tiga indikator penilaian kinerja penyuluh yaitu: persiapan penyuluhan pertanian, pelaksanaan penyuluhan pertanian dan evaluasi pelaporan penyuluhan pertanian. Hasil pada penelitian ini secara rata-rata penilaian dari klasifikasi kinerja PPL masuk dalam klasifikasi cukup baik. dan klasifikasi kinerja PPL berdasarkan masing-masing indikator disajikan pada Tabel 1.

Tabel 1 menunjukkan bahwa kinerja PPL masuk dalam klasifikasi cukup baik. Penyuluh cukup rutin melakukan kunjungan 
ke kelompok tani, membantu petani dalam pemecahan masalah dan memberikan penyuluhan sesuai dengan apa yang diharapkan oleh petani. Namun masih ada beberapa PPL yang kinerjanya masih kurang baik karena minimnya pengalaman dan rasa keinginan melakukan penyuluhan yang rendah, PPL yang kinerjanya tergolong kurang baik sebagian besar adalah PPL lakilaki. Menurut pengamatan di lapangan dan pendapat salah seorang petani hal tersebut dikarenakan jauhnya lokasi wilayah kerja dari masing-masing PPL dan tidak tersedianya prasarana sehingga membuat PPL sulit untuk menuju lokasi wilayah kerja.

Tabel 1.

Klasifikasi kinerja PPL menurut pendapat PPL dan petani

\begin{tabular}{llcc}
\hline \multicolumn{1}{c}{ Skor } & Klasifikasi & $\begin{array}{c}\text { Responden } \\
\text { (orang) }\end{array}$ & $\begin{array}{c}\text { Persentase } \\
(\%)\end{array}$ \\
\hline $\begin{array}{l}31,350- \\
33,761\end{array}$ & Baik & 2 & 50 \\
$28,938-$ & Cukup baik & 1 & 25 \\
31,349 & & \\
$26,525-$ & Kurang baik & 1 & 25 \\
28,937 & & 4 & 100 \\
\hline Jumlah & & \\
\hline $\begin{array}{l}\text { Rata-rata }=30,294 \\
\text { (Cukup baik) }\end{array}$ & & \\
\hline
\end{tabular}

Faktor-faktor yang berhubungan dengan Kinerja PPL di BPPP Kecamatan Metro Selatan Kota Metro

Kinerja PPL merupakan respon atau perilaku individu terhadap keberhasilan kerja yang dicapai oleh individu secara aktual dalam suatu organisasi sesuai tugas dan tanggung jawab yang diberikan kepadanya yang dilaksanakan secara efektif dan efisien berdasarkan periode waktu tertentu dalam rangka mencapai tujuan organisasi Amstrong (1998).

Hasil yang diperoleh yaitu variabel usia masuk dalam klasifikasi cukup muda. Hal ini menunjukkan kinerja penyuluh pertanian lapangan dalam kategori umur tergolong cukup baik. Pada penelitian ini PPL yang berumur tua justru kinerjanya lebih baik dari PPL yang berumur muda, hal tersebut dikarenakan PPL yang berumur tua lebih banyak pengalaman dibandingkan dengan PPL yang berumur muda. Hasil kinerja PPL pada penelitian ini bertolak belakang dengan teori yang ada yaitu menurut Amron (2009), tenaga kerja yang berumur tua mempunyai tenaga fisik yang lemah dan terbatas, sebaliknya tenaga kerja yang berumur muda mempunyai kemampuan fisik yang kuat dan baik.

Variabel tingkat pendidikan dan status PPL masuk dalam klasifikasi tinggi dan ketersediaan sarana dan prasarana masuk dalam klasifikasi memadai. Variabel masa kerja masuk dalam klasifikasi cukup lama. Hasil turun lapang mengindikasikan bahwa penyuluhan yang diberikan oleh PPL menurut petani sudah cukup baik. Penyuluhan yang diberikan PPL sudah cukup menyebar merata. Klasifikasi faktorfaktor yang diduga berhubungan dengan kinerja PPL disajikan pada Tabel 2.

Tabel 2.

Karakteristik Individu PPL yang berhubungan dengan kinerja PPL

\begin{tabular}{cccc}
\hline Kinerja PPL & $\begin{array}{c}\text { Nilai } \\
\text { tertinggi }\end{array}$ & $\begin{array}{c}\text { Nilai } \\
\text { rata- } \\
\text { rata }\end{array}$ & Klasifikasi \\
\hline Usia & 52 thn & 45 thn & $\begin{array}{c}\text { Cukup } \\
\text { muda }\end{array}$ \\
$\begin{array}{c}\text { Tingkat } \\
\text { pendidikan } \\
\text { Masa kerja }\end{array}$ & Sarjana & Sarjana & $\begin{array}{c}\text { Tinggi } \\
\text { Cukup }\end{array}$ \\
$\begin{array}{c}\text { Ketersediaan } \\
\text { sarana dan } \\
\text { prasarana } \\
\text { (skor) }\end{array}$ & 3 & 16 thn & $\begin{array}{c}\text { Lama } \\
\text { Status PPL }\end{array}$ \\
\hline & PNS & 3 & Memadai \\
\hline
\end{tabular}

\section{Tingkat Kepuasaan Petani padi terhadap Kinerja PPL}

Pembangunan pertanian khususnya padi pada proses pembudidayaannya sangat membutuhkan peran penyuluh pertanian. Membantu petani dalam mengusahatanikan padi sesuai dengan teknologi budidaya pertanian yang berorientasi pada pengetahuan, kemampuan dan sikap petani dalam mengadopsi teknologi pertanian. Membangun sumberdaya manusia pertanian yang berkualitas dan handal, diperlukan 
penyuluhan pertanian yang profesional, kreatif, inovatif dan berwawasan global dalam penyelenggaraan penyuluhan yang produktif, efektif dan efisien.

Kinerja penyuluh yang baik akan menghasilkan kepuasan bagi petani. Jika petani puas dengan kinerja penyuluh maka akan bersemangat dalam meningkatkan usahataninya. Produksi yang tinggi dapat meningkatkan hasil pendapatan petani.

Tingkat kepuasan petani dapat dilihat dari penilaian kinerja yang dihasilkan oleh PPL. Penilaian kinerja penyuluh dapat dinilai berdasarkan teori Kotler (2009), yaitu berwujud (Tangible), keandalan (Reability), kesigapan (Responsiveness), kepastian (Assurance) dan empati (Empathy). Hasil pada penelitian ini secara rata-rata penilaian masuk dalam klasifikasi cukup puas, disajikan pada Tabel 3.

\section{Tabel 3}

Klasifikasi kepuasan petani padi terhadap kinerja penyuluh

\begin{tabular}{lcc}
\hline Kepuasaan petani & Klasifikasi & $\begin{array}{c}\text { Responden } \\
\text { (orang) }\end{array}$ \\
\hline $63,676-72,483$ & Puas & 24 \\
$54,868-63,675$ & Cukup puas & 18 \\
$46,059-54,867$ & Kurang & 21 \\
& puas \\
\hline \multicolumn{2}{l}{ Jumlah Responden } & 63 \\
\hline Rata-rata $=59,491$ (Cukup puas) \\
\hline
\end{tabular}

Berdasarkan Tabel 3, kepuasaan petani padi terhadap kinerja PPL berada pada klasifikasi cukup puas dengan dengan nilai rata-rata 59,49 masuk dalam klasifikasi cukup puas. Hal tersebut menunjukkan bahwa kinerja PPL tergolong cukup puas. Kinerja PPL sudah cukup baik karena penyuluh cukup rutin melakukan kunjungan ke kelompok tani, membantu petani dalam pemecahan masalah dan memberikan penyuluhan sesuai dengan apa yang diharapkan oleh petani.

Beberapa petani berpendapat bahwa mereka kurang puas dengan kinerja PPL, karena ada PPL yang selama musim tanam tidak berkunjung ke petani sehingga dalam menghadapi masalah yang dihadapi petani hanya memecahkan dengan kelompok saja tanpa didamping oleh PPL. PPL yang kinerjanya tergolong kurang sebagian besar memiliki masa kerja lebih sedikit dibanding PPL yang sudah lama bekerja. Menurut pendapat salah seorang petani hal tersebut dikarenakan pengalaman penyuluh yang masih kurang.

PPL dengan masa kerja yang sedikit kurang memberikan perhatian khusus untuk individual atas masalah tertentu (khusus), terkadang penyuluh sulit ditemui untuk berkonsultasi langsung dikarenakan jauhnya lokasi wilayah kerja dari masing - masing PPL dan tidak tersedianya prasarana sehingga membuat PPL sulit untuk menuju lokasi wilayah kerja. Penjabaran di atas seharusnya BPPP Kecamatan Metro Selatan dalam menentukan wilayah binaan PPL lebih mempertimbangkan lokasi rumah PPL. PPL yang kinerjanya tergolong kurang sebagian besar PPL laki-laki (dapat di lihat pada Tabel 1) menurut pendapat salah seorang petani hal tersebut dikarenakan jauhnya lokasi wilayah kerja dari masingmasing PPL dan tidak tersedianya prasarana sehingga membuat PPL sulit untuk menuju lokasi wilayah kerja.

\section{Faktor-Faktor yang Berhubungan dengan Kinerja PPL}

Faktor-faktor yang berhubungan dengan kinerja PPL dengan variabel Y dianalisis dengan menggunakan uji korelasi Rank Spearman dengan bantuan SPSS 24. Hasil pengujian Rank Spearman dapat dilihat pada Tabel 4 .

Tabel 4 menjelaskan bahwa usia PPL, tingkat pendidikan dan status PPL tidak berhubungan nyata dengan kinerja PPL. Hasil ini sejalan dengan penelitian Santi (2016), yang menyatakan bahwa tingkat pendidikan tidak berhubungan nyata dengan kinerja PPL, namun bertolak belakang dengan penelitian Praja (2015), yang menyatakan tingkat pendidikan berhubungan nyata dengan kinerja PPL.

Sejalan dengan penelitian Sari (2017), yang menyatakan bahwa masa kerja berhubungan nyata dengan kinerja PPL. 
Hasil uji analisis variabel yang berhubungan dengan kinerja penyuluh pada penelitian ini yaitu variabel masa kerja PPL dan ketersediaan sarana dan prasarana PPL.

Tabel 4.

Hubungan antara variabel $\mathrm{X}$ dengan variabel Y

\begin{tabular}{ccccc}
\hline Variabel X & Variabel & $\begin{array}{c}\text { Koefisie } \\
\mathrm{n} \\
\text { Kolerasi } \\
(\mathrm{rs})\end{array}$ & $\begin{array}{c}\text { Sig } \\
(2- \\
\text { tailed })\end{array}$ & $\alpha$ \\
\hline $\begin{array}{c}\text { Usia PPL } \\
\text { Tingkat Pendidikan }\end{array}$ & & 0.894 & 0.106 & 0.05 \\
$\begin{array}{c}\text { PPL } \\
\text { Masa Kerja }\end{array}$ & Kinerja & 0.894 & 0.106 & 0.05 \\
$\begin{array}{c}\text { Ketersediaan Sarana } \\
\text { dan Prasarana }\end{array}$ & PPL & 1.000 & 0.000 & 0.05 \\
Status PPL & & 1.000 & 0.000 & 0.05 \\
\hline & & -0.258 & 0.742 & 0.05 \\
\hline
\end{tabular}

Sejalan dengan penelitian Sari (2017), yang menyatakan bahwa masa kerja berhubungan nyata dengan kinerja PPL. Hasil uji analisis variabel yang berhubungan dengan kinerja penyuluh pada penelitian ini yaitu variabel masa kerja PPL dan ketersediaan sarana dan prasarana PPL.

Menurut hasil lapangan di BPPP Kecamatan Metro Selatan, PPL yang pendidikannya lebih tinggi tidak menjamin kinerja yang dihasilkan lebih baik dari PPL yang pendidikannya lebih rendah. Apabila PPL memiliki tingkat pendidikan tinggi namun minim pengalaman, dibandingkan dengan PPL yang tingkat pendidikan lebih rendah namun banyak pengalaman, tentu kinerjanya akan lebih baik PPL yang rendah pendidikannya namun banyak pengalaman. Semakin banyak pengalaman yang dimiliki maka PPL akan lebih mudah memahami kondisi dilapangan dan sudah lebih memahami karakteristik petani, sehingga dalam penyampaian materi penyuluhan akan lebih tepat sasaran dan sesuai dengan yang diharapkan oleh petani.

\section{Hubungan antara Tingkat Kinerja PPL dengan Tingkat Kepuasaan Petani}

Hasil pengujian hipotesis hubungan antara kinerja PPL (Y) dengan tingkat kepuasan petani padi (Z) menunjukkan adanya hubungan nyata dengan tingkat kepercayaan $95 \%$. Hasil pengujian hipotesis pada penelitian ini disajikan pada Tabel 5.
Tabel 5 menjelaskan bahwa kinerja PPL berhubungan nyata dengan tingkat kepuasaan petani padi dengan nilai koefisien korelasi 0.782 dan nilai signifikan sebesar 0.000 yang berarti lebih kecil dari $\alpha$ sebesar 0.05. Semakin baik kinerja PPL maka akan semakin tinggi tingkat kepuasaan petani padi terhadap kinerja PPL.

Tabel 5.

Hubungan antara variabel $\mathrm{Y}$ dengan variabel $\mathrm{Z}$

\begin{tabular}{cccccc}
\hline $\begin{array}{c}\text { Variabel } \\
\mathbf{Y}\end{array}$ & $\begin{array}{c}\text { Variabel } \\
\mathbf{Z}\end{array}$ & $\begin{array}{c}\text { Koefisien } \\
\text { Kolerasi } \\
(\mathbf{r s})\end{array}$ & $\begin{array}{c}\text { Sig } \\
(2-\text {-tailed })\end{array}$ & $\boldsymbol{\alpha}$ & $\begin{array}{c}\text { Keputu } \\
\text { san }\end{array}$ \\
\hline $\begin{array}{c}\text { Kinerja } \\
\text { PPL }\end{array}$ & $\begin{array}{c}\text { Kepuasan } \\
\text { petani } \\
\text { padi }\end{array}$ & 0.782 & 0.000 & 0.05 & $\begin{array}{c}\text { diteri } \\
\text { ma }\end{array}$ \\
& & & & & \\
\hline
\end{tabular}

\section{SIMPULAN}

Kinerja penyuluh pertanian lapangan di Kecamatan Metro Selatan tergolong cukup baik. Penyuluh cukup rutin melakukan kunjungan ke kelompok tani, membantu petani dalam pemecahan masalah dan memberikan penyuluhan sesuai dengan apa yang diharapkan oleh petani. Tingkat kepuasan petani padi terhadap kinerja penyuluh pertanian lapangan tergolong cukup puas. PPL sudah memberikan penyuluhan yang cukup sesuai dengan apa yang diharapkan oleh petani. Faktor-faktor yang berhubungan dengan kinerja penyuluh pertanian lapangan pada penelitian ini adalah masa kerja PPL dan ketersediaan sarana dan prasarana (gedung, laptop, lcd, kendaraan dll). Tingkat kinerja penyuluh pertanian lapangan memiliki hubungan dengan tingkat kepuasan petani padi. Semakin tinggi tingkat kinerja PPL maka semakin tinggi pula tingkat kepuasan petani padi terhadap kinerja PPL.

\section{DAFTAR PUSTAKA}

Amron. 2009. Analisis Faktor-Faktor yang Berpengaruh Terhadap Produktivitas Tenaga Kerja pada Outlet Telekomunikasi Seluler Kota Makasar. Jurnal Sekolah Tinggi Ilmu Ekonomi Nobel Indonesia. 
Amstrong. 1998. Performance Management The New Realities. London: Institute of Personnel and Development.

Badan Ketahanan Pangan. 2016. Peraturan Pemerintah Republik Indonesia Nomor 68 Tahun 2016 Tentang Ketahanan Pangan. Jakarta.

Badan Pusat Statistik. 2018. Data Produksi Padi tingkat provinsi. Badan Pusat Statistik Indonesia. Indonesia

Departemen Pertanian. 2009. Dasar-dasar Penyuluhan Pertanian. Modul Pembekalan Bagi THL-TB Penyuluh Pertanian 2009. Departemen Pertanian Badan Pengembangan Sumberdaya Manusia Pertanian. Jakarta.

Dinas Pertanian Perikanan dan Kehutanan. 2017. Data Produksi Padi tingkat kota. Dinas Pertanian Perikanan dan Kehutanan Kecamatan Metro Selatan.

Kotler, Philip. Manajemen Pemasaran. Jakarta : Erlangga

Peraturan Mentri Pertanian. 2013. Pedoman Evaluasi Kinerja Penyuluh Pertanian nomer 91 tahun 2013. Peraturan Mentri Pertanian Nomor 91/Permentan/OT.140/2013.

Praja., F. B, Gitosaputro dan Listiana.2015. Efektivitas Program Pengembangan BP3K Sebagai Model Center Of Excelence (Coe) dalam Peningkatan
Kinerja Penyuluh di Kecamatan Batanghari, Kabupaten Lampung Timur. JIIA, Volume 3 No. 2, Oktober 2015. Universitas Lampung.

Purnomojati Anggorosetyo. 2012. Faktorfaktor yang Mempengeruhi Kinerja Penyuluh Dalam Pemanfaaatan Cyber Extention di Kabupaten Bogor. Tesis. Program Pascasarjana UNS.

Rangkuti. F. 2006. Riset Pemasaran. Edisi Ketiga. PT. Gramedia, Jakarta.

Santi, Nikmatullah dan Pradyitno 2016. Tingkat Kinerja Penyuluh Pertanian Tanaman Pangan di BP3K Kecamatan Gadingrejo Kabupaten Pringsewu. JIIA, Volume 4 No. 3, Agustus 2016. Universitas Lampung.

Sari., D. A, Nikmatullah dan Silviyanti. 2017. Kinerja Penyuluh Pertanian Lapangan dalam Melaksanakan Tugas Pokok Penyuluh di BP3K Kecamatan Banjar Baru Kabupaten Tulang Bawang. JIIA, Volume 5 No 4, November 2017. Universitas Lampung.

Siegel. 1997. Statistik Non Parametik. Jakarta: Gramedia 